\title{
Clouds, circulation and climate sensitivity
}

Article

Accepted Version

Author final version after peer review corrections

Bony, S., Stevens, B., Frierson, D. M. W., Jakob, C., Kageyama, M., Pincus, R., Shepherd, T. G., Sherwood, S. C., Siebesma, A. P., Sobel, A. H., Watanabe, M. and Webb, M. J. (2015) Clouds, circulation and climate sensitivity. Nature Geoscience, 8 (4). pp. 261-268. ISSN 1752-0894 doi: https://doi.org/10.1038/NGEO2398 Available at https://centaur.reading.ac.uk/39925/

It is advisable to refer to the publisher's version if you intend to cite from the work. See Guidance on citing.

To link to this article DOI: http://dx.doi.org/10.1038/NGEO2398

Publisher: Nature Publishing Group

All outputs in CentAUR are protected by Intellectual Property Rights law, including copyright law. Copyright and IPR is retained by the creators or other copyright holders. Terms and conditions for use of this material are defined in the End User Agreement.

www.reading.ac.uk/centaur

\section{CentAUR}

Central Archive at the University of Reading 
Reading's research outputs online 


\section{Clouds, Circulation and Climate Sensitivity}

2 Sandrine Bony ${ }^{1, *}$, Bjorn Stevens ${ }^{2}$, Dargan M. W. Frierson ${ }^{3}$, Christian Jakob ${ }^{4}$,

3 Masa Kageyama $^{5}$, Robert Pincus ${ }^{6}$, Theodore G. Shepherd ${ }^{7}$, Steven C. Sherwood ${ }^{8}$,

4 A. Pier Siebesma ${ }^{9}$, Adam H. Sobel ${ }^{10}$, Masahiro Watanabe ${ }^{11}$, Mark J. Webb ${ }^{12}$

${ }_{5}{ }^{1}$ LMD/IPSL, CNRS, Université Pierre et Marie Curie, Paris, France

${ }_{6}^{2}$ Max Planck Institute for Meteorology, Hamburg, Germany

${ }^{3}$ Department of Atmospheric Sciences, University of Washington, Seattle, USA

$8{ }^{4}$ School of Mathematical Sciences, Monash University, Clayton, Australia

${ }^{5}$ LSCE/IPSL, CNRS, CEA, Gif-sur-Yvette, France

${ }^{6}$ NOAA Earth System Research Lab, University of Colorado, Boulder, USA

${ }^{7}$ Department of Meteorology, University of Reading, Reading, UK

${ }^{8}$ CCRC and Centre of Excellence for Climate System Science, Univ. New South Wales, Sydney, Australia

${ }^{9}$ KNMI, De Bilt, The Netherlands

${ }^{10}$ Department of Applied Physics and Applied Mathematics, Columbia University, New York, USA

${ }^{11}$ Atmosphere and Ocean Research Institute, University of Tokyo, Chiba, Japan

${ }^{12}$ Hadley Centre, Met Office, Exeter, UK

Fundamental puzzles of climate science, such as our inability to provide robust assessments of future global and regional climate changes, are rooted in our limited understanding of how clouds, circulation and climate interact. Recent advances in our capacity to observe, simulate and conceptualize the climate system now make it possible to improve this understanding. We argue that by focussing research on a handful of important scientific questions, particularly those that have become more tractable as a result of recent advances, will accelerate progress. Four such questions are outlined below. They aim at understanding the role of cloud feedbacks and convective organization in climate, and the factors that control the position, the strength and the variability of the tropical rain belts and the extra-tropical storm tracks. 
Clouds stimulate the human spirit. Recognised for centuries as harbingers of weather, only in recent decades have scientists begun to appreciate their role in determining the general circulation of the atmosphere and its susceptibility to change.

Forming mostly in the updrafts of the turbulent and chaotic air-flow, clouds embody the complex and multi-scale organisation of the atmosphere into dynamical entities, or storms. These entities are responsible for mediating the radiative transfer of energy, distributing precipitation, and are often associated with extreme winds. It has long been recognized that water and the diabatic processes it mediates play a fundamental role in tropical circulations, and there is increasing evidence that they also influence extra-tropical circulations ${ }^{1}$. Globally, the impact of clouds on Earth's radiation budget and hence surface temperatures, also depends critically on how clouds interact with one another and with larger scale circulations ${ }^{2}$. Far from being passive tracers of a turbulent atmosphere, clouds thus embody processes that can actively control circulation and climate (Box 1).

For practical reasons, early endeavours to understand climate deployed a divide and conquer strategy in which efforts to understand clouds and convective processes developed separately from efforts to understand larger-scale circulations. Over time, a gap developed between the sub-disciplines. However, technological progress and conceptual advances have tremendously increased our capacity to observe and simulate the climate system, such that it is now possible to study more readily how small-scale convective processes - that is, clouds - couple to large-scale circulations (see Box 2). Much like a new accelerator allows physicists to explore the implication of the interactions among forces acting over different length scales, these new capabilities are transforming how atmospheric scientists think about the interplay of clouds and climate. This offers a great opportunity not only to close the gap between scientific communities, but also to answer some of the most pressing questions about the fate of our planet. 


\section{Urgent need for accelerated progress}

Climate is changing at an unprecedented pace ${ }^{3}$. Government and private decision makers involved in planning and risk assessments urgently need information about how rapidly temperatures will rise, how rainfall patterns will change, and whether the frequency of extreme weather will increase. Climate scientists have built a successful research framework for detecting and attributing some global aspects of climate change, such as the basic trends in globally averaged temperatures and sea level. This success is reflected in the growing level of confidence in understanding of such changes ${ }^{3}$. However this framework is much less effective when it comes to quantifying critical aspects of climate change such as the climate sensitivity or regional changes. On these aspects, observational data sets are limited, natural variability obscures the anthropogenic signal, and climate models produce uncertain projections ${ }^{4,5}$. This leads to a low confidence in their assessment ${ }^{3}$.

A deeper understanding of how clouds and aerosols affect the planetary energy budget is needed if we are to increase our confidence in these fundamental aspects of climate change ${ }^{6,7}$. However, given the strong dependence of regional climate patterns and extremes on the large-scale circulation, it is equally important to better understand how clouds and convection affect atmospheric dynamics and its change as the troposphere becomes warmer and wetter, the stratosphere colder and the cryosphere smaller ${ }^{4,8}$ (Box 1). Our degree of understanding of the interplay between clouds, circulation and climate sensitivity thus demarcates the frontiers of our ability to anticipate climate changes.

Numerical models have always played an important role in climate change studies and assessments. However, robust conclusions require more than a consensus by the most comprehensive models. They require the underpinning of physical arguments -theoriesdeveloped through the use of a hierarchy of models and critically assessed using available data ${ }^{6,9}$. An increased emphasis on understanding may well be the best course of action to develop reliable insights about climate change, but also to address their urgent need. Con- 
ceptual breakthroughs have typically come from rephrasing old questions in a new way, one that makes long-standing problems finally tractable. Advances in key issues such as the extent of the Hadley cell ${ }^{10}$, the intensity of tropical cyclones ${ }^{11}$, or the height reached by convective clouds ${ }^{12}$, have all come through idealized studies and clever application of physical reasoning to obtain constraints on the system, leading to new ways of using and interpreting comprehensive models, and linking them to observations. We argue therefore that accelerating progress in climate change assessments requires an approach focused on the development and testing of hypotheses that link changes in regional patterns, extremes, climate sensitivity, and other important features of climate in a self-consistent way. The theories or 'story lines' that emerge from such an approach emphasize physical concepts and testable ideas around which scientific activity can organise, and may also make communication of risk-based assessments more concrete.

By focusing the development of story lines around a few carefully chosen questions, a more comprehensive analysis will be possible, one in which the integration of observations, evidence obtained from a hierarchy of models, and physical understanding will advance knowledge much more efficiently than would the consideration of particular lines of evidence in isolation. Below, four such questions are outlined. Among the great variety of questions one might consider, these four stood out both because of their centrality to a more specific understanding of global and regional climate changes, and because new and emerging approaches or insights are, as outlined below, making them more tractable.

\section{Four Questions}

\section{* What role does convection play in cloud feedbacks?}

Many changes of the climate system at global and regional scales are mainly determined by the globally averaged temperature. For this reason, one of the simplest and most important measures of the system response to forcing remains the "climate sensitivity", 
i.e., the equilibrium change in the globally averaged near-surface temperature in response to a doubling of the concentration of atmospheric $\mathrm{CO}_{2}$. Available evidence suggests a range in the climate sensitivity from 1.5 to $4.5 \mathrm{~K}^{3}$. The socio-economic implications of this uncertainty are enormous - a simple calculation demonstrates that to maintain a warming target of two degrees, nearly twice as much $\mathrm{CO}_{2}$ could be emitted in a low (1.5 $\mathrm{K})$ climate sensitivity world as compared to a high $(4.5 \mathrm{~K})$ sensitivity world. Economic modelling suggests that progress in the assessment of climate sensitivity would have a staggering economic value ${ }^{13}$.

Although the likely range of climate sensitivity estimates has not narrowed in the past three decades, tremendous progress has been made in understanding the factors controlling climate sensitivity ${ }^{6,7}$. It is now possible to delineate between well understood processes, which contribute to a base value of about $2.7 \mathrm{~K}^{14}$, from more poorly understood processes - largely cloud feedbacks.

Cloud feedbacks could be described as the climate systems equivalent of Winston Churchills Russia: "a riddle wrapped inside a mystery inside an enigma. Over the past decades at least some aspects of cloud feedbacks have at least become less enigmatic. Mechanisms governing the height of the deepest clouds are now much better understood ${ }^{12}$. Feedbacks from clouds in the planetary boundary layer over oceans (Fig. 1), which make one of the largest contributions to inter-model spread in climate sensitivity, appear to be driven largely by mixing of the lower troposphere by shallow convection ${ }^{2,15-17}$; in a warmer climate these processes are expected to dry the marine boundary layer over the vast expanse of the tropical oceans, reducing the low-cloud amount and the Earth's albedo in a way that amplifies warming. These and other cloud feedback processes are increasingly understood as being mediated by changes in atmospheric circulations rather than by, for example, microphysical effects ${ }^{7}$.

This emerging narrative may make cloud feedbacks less enigmatic, but leaves the mystery as to the nature of the interplay between clouds and convection. This riddle is 
manifest in the tendency of models to exhibit a large degree of freedom in their prediction of upper-level cloud cover responses ${ }^{18}$, and in their representation of shallow convective mixing, which appears to determine the strength of their low-cloud feedbacks ${ }^{2}$. Convective mixing processes have been found to be important in explaining the distribution of the tropical rain belts, and may also affect climate (temperature) and hydrological (rainfall) sensitivity through processes currently missing or poorly represented in climate models - for instance convective scale organization, or processes related to the distribution of clouds at mid to upper levels. Might the presently crude representation of convective mixing processes in models be missing important cloud feedback mechanisms?

These ideas could be tested by suppressing or altering processes in comprehensive models in ways that are guided by results from observations or more fundamental models. One could then ask to what extent the broader implications of such processes are consistent with other things we know. So doing would help explain how much of the model spread can be attributed to differences in convective parameterizations, or whether poor parameterizations (or simply the absence of critical processes) are skewing our prediction of the system. Increasingly specific ideas could also guide the collection and analysis of Earth observations, for instance through field experiments focusing on undisturbed conditions in the maritime tropics or improved space based estimates of lower tropospheric water vapour.

\section{* What controls the position, strength and variability of storm tracks?}

Extratropical storms draw their energy from the temperature contrast between the equator and poles. They are associated with the familiar high and low pressure systems of the midlatitudes, with their attendant temperature fronts, precipitation, and sometimes severe weather. Most extra-tropical storms develop, organise and decay in spatially localised regions known as "storm tracks." The storm tracks tend to be roughly aligned with the global jet streams (upper-level eastward wind currents) and are major components of the general circulation through their role in the meridional transport of energy, moisture 
and momentum, and in the modification of Earth's energy budget through associated patterns of clouds (Fig. 2).

The jets and the storms interact with each other symbiotically, giving rise to lowfrequency variations. One feature of this variability is the emergence of persistent "blocking" events, which effectively reroute storms away from their usual track. Blocking events can be associated with summer heat waves and winter cold snaps over the blocked region, as well as unusual storminess away from the block. Year to year variability in the position of the storm tracks is associated with large swings in temperature: monthly averaged temperatures in the upper mid-west of the United States, for instance, can vary by more than $10{ }^{\circ} \mathrm{C}$ from one year to the next as the storm tracks shift. Likewise, unusual persistence in the path of successive storms can lead to widespread flooding as was the case for the UK in the winter of 2013/2014, or to unseasonably pleasant weather.

The chaotic variations of the storm tracks become manifest as natural weather and climate variability on decadal timescales, which makes it difficult to attribute a change in any given year to changes in the climate. But models and theory do suggest that the storm tracks are sensitive to external forcing, for instance changes in meridional temperature gradients. Near the surface, temperature gradients are expected to weaken as surface warming is stronger near the poles; aloft, temperature gradients will strengthen as the stratosphere cools and the tropical upper troposphere warms. These changes have opposing effects ${ }^{19}$, but on balance models suggest that storm tracks will shift poleward with warming. Support for this line of thinking arises from a discernible poleward shift of summertime precipitation in the Southern Hemisphere, which has been attributed to cooling in the polar stratosphere resulting from the depletion of ozone there ${ }^{20}$. But these shifts are not monolithic, particularly in the Northern Hemisphere where zonal asymmetries are fundamental to an understanding of storm track location ${ }^{21}$. Changes in the zonal asymmetry of the jet can lead to equator-ward shifts in regions ${ }^{22}$ even if, on average, the jet is displaced poleward. 
Even for changes in the jets that models robustly simulate, understanding remains low. Uncertainty in future projections is not surprising as models also exhibit large biases in the simulation of the present day, with storm tracks located too far equatorward and, in the Northern Hemisphere, too zonally oriented ${ }^{23}$. Progress in developing a narrative for future storm track changes will likely depend on progress in understanding the origins and implications of these biases.

Theoretical understanding of extratropical storms is largely based on dry dynamics, but the water that flows through these storms also plays a fundamental role in determining their evolution. Half of the poleward transport of energy within storm tracks is accomplished by the latent heat component, meaning moisture is vital in setting the temperature gradients upon which storms grow. The release of latent heat within the warm sector of storms and in frontal regions has long been understood as an important and additional energy source for cyclogenesis. However the myriad ways in which clouds couple to the storm tracks are just beginning to be appreciated, for instance through their radiative effects. As the clouds embedded within the storm tracks shift, there are systematic implications for the radiation budget and its influence on the temperature gradients that give rise to the storms in the first place ${ }^{24,25}$. The development of a hierarchy of modelling approaches is advancing understanding of how moist processes such as those imbedded along frontal systems, interactions with ocean circulations, and cloud radiative effects, influence both storm development and the structure of the storm tracks. Because storm tracks are large enough to be resolved across these model hierarchies, and very high-resolution approaches can also increasingly resolve convective circulations within the storm system ${ }^{26}$ as well as remote influences from fine-scale orography or changes in tropical circulations, hierarchical modeling approaches hold particular promise for developing story lines of how storm tracks will change in the future.

To gain confidence in these emerging story lines, it will be useful to look to the past. Models suggest that storm tracks have responded to past external forcings ${ }^{27}$. A 
maturing theoretical understanding of these changes, expressed for instance in the form of hypotheses of storm track change during the last-glacial maximum or mid-holocene periods, could be tested using reconstructions of past precipitation changes from pollen records $^{28}$. Developing an understanding of storm-track dynamics that would allow us both to explain the record of past changes and to robustly predict the tendency of a change, would be a significant advance.

\section{* What controls the position, strength and variability of the tropical rain belts?}

In the tropics, rain tends to be concentrated in compact bands or belts (Fig. 3). Over the ocean, the Inter-tropical Convergence Zone (ITCZ) contains some of the rainiest regions on the planet, and some of the deepest cumulonimbus and stratiform anvil clouds. These tropical rain belts are so closely related to the monsoons, which spread the rainy regions more poleward over land, that scientists increasingly think of those monsoons as the terrestrial amplification of the seasonal migration of the rain belts. These climate features directly affect hundreds of millions of people, who depend on rainfall for fresh water.

Tropical rain belts cannot be understood without understanding the roles of the clouds within them. Over the ocean these rain belts are tied to the warmest sea surface temperatures, which favour sustained rising motion as seen in the rising branch of the Hadley and Walker circulations. The high clouds in the rain belts have a strong effect on shortwave radiation due to the amount of condensate, and on long-wave radiation due to their height. These radiative effects influence both sea surface temperature and atmospheric circulation. The breadth of the subsiding branches of tropical over-turning circulations determines the prevalence of low clouds within the broader tropics. Any climate forcing that leads to a change in strength, width, or location of a tropical rain belt is thus potentially associated with a cloud feedback, which will in turn influence the patterns of temperature change and circulation response to the forcing.

Local interactions between the atmosphere and the upper ocean or the land surface 
have long been recognized to play a role in determining the position of the rain belts. However recent work has emphasized that changes in the rain belts' location and intensity are intimately coupled to circulations on a variety of scales. Mesoscale convective circulations appear to influence the poleward extent of the monsoon in ways that are just starting to be undersood ${ }^{29}$, and planetary scale circulations connect the rain belts to processes in distant extra-tropical locations ${ }^{30}$. Newly developed energetic frameworks have proven to be a useful way to understand these connections ${ }^{31}$. Models suggest that high-latitude heat sources, for example, drive atmospheric heat transport through the midlatitudes and into the tropics. There, the Hadley cell responds by transporting energy away from the heating, and moisture toward the heating. This causes tropical rain belts to be displaced toward the heating, even when that heating is located far away. This type of tropical-extratropical interaction may help explain the double-ITCZ problem in climate models, a longstanding bias associated with an overly pronounced southern ITCZ: a deficit in cloudiness over the Southern Ocean warms the entire southern hemisphere, causing excessive precipitation within the southern tropics and driving a stronger ITCZ in the southern hemisphere ${ }^{32}$. This process probably explains why cooling in one hemisphere by aerosols or ice sheet expansion pushes the tropical rain bands toward the opposite hemisphere ${ }^{33}$.

Historical evidence also supports the view that tropical rain bands may be quite mutable. Most strikingly, in the Sahara, vegetation and lake indicators, as well as many examples of rock art, document periods such as the early and mid-Holocene, when the African monsoon extended much further north than today (see Box 2). Although much of this change would seem to be due to changes in insolation driven by precession of Earth's orbit, this factor alone is insufficient to explain the shift in today's climate models, even when vegetation feedbacks are taken into account ${ }^{34}$. Past ITCZ shifts may be poorly simulated at other time periods as well, e.g., the Last Glacial Maximum ${ }^{35}$. Insufficient understanding, and uncertainties in past climate reconstructions, make it difficult to assess modelled responses. Hence, developing a story line for future changes in tropical rain bands will be a challenge, one that seems unlikely to be met without coordinated efforts 
using a hierarchy of models to work through specific hypotheses motivated by more robust evidence of past changes.

\section{* What role does convective aggregation play in climate?}

Satellite imagery offers an inexhaustible opportunity to admire the vast variety of ways in which moist convection is organised: from randomly scattered small clouds, to clusters of convective cells forming in arcs, bands or whirls on mesoscales, as well as large-scale cloud systems which trace circulations on the planetary scale. The propensity of convection to aggregate and organise has long been related to the variability of weather and to the occurrence of extreme rainfall events. The idea that the organization of moist convection might play a role in the dynamics of the climate system is not a new one. Insights from field studies dating to the dawn of the satellite era have suggested that tropical convective clusters affect vertical profiles of atmospheric heating significantly enough to influence circulations on much larger scales ${ }^{36}$.

Idealised numerical studies have led to renewed interest in the subject of organization. These studies demonstrate that convection can aggregate spontaneously even in the absence of external drivers (Fig. 4), leading to the concept of "self-aggregation"37. These studies, and observational analyses inspired by them, suggest that the degree of aggregation of a given amount of convection influences the mean atmospheric state: an atmosphere in which convection is more aggregated is drier, clearer, and more efficient at radiating heat to space ${ }^{37,38}$. Cloud-resolving simulations further suggest that self-aggregation might increase with temperature ${ }^{39}$. If so, convective aggregation could feed back on climate changes driven by other influences, and may contribute to changes in extreme events.

The tendency of deep convection to organise may also influence the general atmospheric circulation. Because convection often organises in a way that modulates the energetics of the atmosphere, the presence of organization on scales of a few tens to several hundreds of kilometers may influence the strength of larger-scale vertical motions and per- 
haps the structure of the tropical rain belts. Another hypothesis is that long-standing riddles, like the Madden-Julian Oscillation (a 30-60 day oscillation of rainfall patterns in the tropical Indo-Pacific region) are a large-scale manifestation of convective self-aggregation.

Observations and numerical simulations at very high resolution are showing that the convective organization is also important for the development of precipitation from shallow convection ${ }^{40}$. Such organization buffers the response of clouds to perturbations in the aerosol environment, or changes in surface fluxes. Likewise, because the effects of shallow cloud cover on radiation can help organize deep convection ${ }^{41}$ and influence the structure of tropical convergence zones ${ }^{42}$, the organization of convection on a wide range of scales may create an interesting link between the cloud feedback and the tropical rain belt questions.

Highly resolved simulations offer opportunities to develop and test an emerging narrative on the role of convective organization. By using such very high-resolution approaches to more fundamentally understand the physical processes underlying aggregation, it may be easier to introduce compelling representations of aggregating processes in large-scale models, or disaggregating processes in the highly resolved simulations. Such approaches would enable numerical experiments aimed at assessing whether or not, and if so how, convective aggregation matters for climate. And these experiments can form the basis for improving the design of field experiments, or informing the analysis of existing data, so as to test the story lines that develop from the modelling.

\section{A Grand Challenge}

For a system as complex as the Earth, posing the right questions-ones that will most effectively advance the science-may well be the greatest challenge. One can certainly argue for additional questions, but we have no doubt that our science and the broader society would be well served even if it only focused on the four posed here. Regardless 
of the questions one poses, meta-scientific challenges must also be addressed to make progress.

First, general circulation models constitute one of the pillars of climate science. Shortcomings in their representation of clouds, precipitation and circulation have persisted for many generations of models ${ }^{43}$, and cause significant problems that remain even when other complexities in the system are stripped away ${ }^{5}$. To gain the most from comprehensive modelling approaches requires energising model development efforts around those processes that most affect the simulation of storm tracks, tropical rain belts and climate sensitivity. Focusing model development efforts around a small set of questions, such as the four articulated above, stands the best chance of reducing long-standing model biases and uncertainties. In the long run, such an approach will also advance the utility of global modelling more broadly, since questions like the future of the permafrost layers, or the dynamics of the terrestrial and ocean carbon sinks depend very much on the magnitude of warming and the distribution of precipitation.

Second, the numerous scales and boundless diversity of processes that challenge the modelling also challenge observing systems. Better understanding will highlight gaps or weaknesses in these systems, and therefore will help prioritise the needs for new observations, imaginative field campaigns, or novel reconstructions, synthesis or interpretations of the long-term palaeo-climatic data records. Here again, developing a consensus around the pursuit of a few questions may disproportionately advance the field, for instance by better identifying the needs and opportunities for advancing the palaeo or satellite records.

Finally, the convergence of two scientific cultures, one concerned with small-scale convective processes, the other with large-scale climate processes, is the result of an increasing capacity to simulate and observe a range of scales that encompasses both, and thereby study their interaction more fundamentally (see Box 2). By linking water to circulation, this convergence can will lead to important advances in Earth system science. 
As envisioned by Edward Lorenz forty-five years ago ${ }^{44} 1$, a deeper understanding of how clouds and moist processes interact with the circulation might help us think about largescale dynamics as a dynamics of water systems, a way of thinking that we believe is a pre-requisite for our science as it endeavours to help a society in urgent need of information about Earth's changing climate.

\section{Box 1: How do clouds and circulation interact?}

The influence of the large-scale atmospheric circulation on clouds has long been recognized, and is evident on any satellite picture (Figure 5). In the extratropics, large cloudsystems are caught up in and trace the motions associated with baroclinic and mesoscale waves. In the tropics, clusters of deep clouds trace the ascending branches of the HadleyWalker circulation, while low clouds cover the ocean in anticyclonic areas. But clouds are not merely sentinels of the circulation, they are increasingly understood to influence and shape the very circulations in which they are embedded. The interaction between clouds and circulation primarily results from three processes: phases changes, radiative transfer, and turbulent transport of air parcels. Condensation and evaporation processes associated with the formation, the maturation or the dissipation of clouds, and the interaction of clouds with solar and infrared radiation, lead to atmospheric heating and cooling perturbations, which stimulate waves and turbulence and which affect the horizontal and vertical distributions of temperature on a wide range of scales. In addition, the mesoscale up- and down-draughts that form within cloud systems transport heat, moisture and momentum, and thus rectify the large-scale atmospheric state. Through these various effects, clouds influence both locally and remotely the atmospheric static stability, the wind shear and the meridional gradients of temperature. In doing so they help determine the localization

\footnotetext{
${ }^{1}$ The previous generation was greatly concerned with the dynamics of pressure systems and talked about highs and lows. Today we have not lost interest in these systems but we tend to look upon them as circulation systems. This change in attitude has led to a deeper understanding of their dynamics. Perhaps the next generation will be talking about the dynamics of water systems. (Lorenz, 1969)
} 
and strength of large-scale dynamical features such as the tropical Hadley-Walker circulation, intra-seasonal oscillations and mid-latitude jets ${ }^{25,32,45,46}$ and influence the rate of development, the structure and the strength of smaller-scale disturbances such as tropical and extra-tropical cyclones, as well as the organization of convection and the occurrence of a range of mesoscale phenomena ${ }^{1,41,47,48}$. New opportunities now make it possible to improve significantly the understanding of these interactions (Box 2).

\section{Box 2: New Opportunities for Rapid Progress}

The clouds-and-circulation problem has been a challenge for a long time, but new opportunities make us confident that a more rapid progress is now possible. Increasing computer power is allowing the representation of motions on the scale of less than a kilometre over domains of thousands of kilometres, even extending to the entire globe (Fig. 6a). Such ultra high-resolution simulations on climate time scales will make it possible to generate clouds and large-scale circulation in a physically consistent manner, and thus to study their interaction. Recent advances in observational capability, particularly satellite measurements with active remote sensing, have removed ambiguity in the passive sensing of cloud and atmospheric structure, and enabled a view of how clouds of different depths couple to their large-scale environment (Fig. 6b). Advances in methods of data assimilationthe optimal synthesis of models and observations - are also able to make increasing use of satellite measurements, soon including direct measurements of winds, which provides increasingly consistent and complete pictures of clouds and circulation. Advances in the identification and interpretation of isotopic signatures, available in both the palaeoclimate record and the present day, are giving impetus to investigations of past climate changes (Fig. 6c). Simulations of past and future climates are now being performed using the same models, offering "out-of-sample" tests of our understanding of the role of clouds and circulation in climate dynamics ${ }^{49}$. Finally, new methodologies of comparison between simulations and observations are now allowing us to not only identify model errors, but to also better interpret their sources ${ }^{50}$. 
1. Emanuel, K. The role of water in atmospheric dynamics and climate. In Pearce, R. P. (ed.) Meteorology at the Millennium, 1-14 (Academic Press, London, 2002).

2. Sherwood, S. C., Bony, S. \& Dufresne, J.-L. Spread in model climate sensitivity traced to atmospheric convective mixing. Nature 505, 37-42 (2014).

3. IPCC 2013. Summary for Policymakers. In Stocker, T. et al. (eds.) Climate Change 2013: The Physical Science Basis. Contribution of Working Group I to the Fifth Assessment Report of the Intergovernmental Panel on Climate Change, 1-29 (Cambridge University Press, Cambridge, United Kingdom and New York, NY, USA., 2013).

4. Shepherd, T. G. Atmospheric circulation as a source of uncertainty in climate change projections. Nature Geoscience 7, 703-708 (2014).

5. Stevens, B. \& Bony, S. What are climate models missing? Science 340, 1053-1054 (2013).

6. Bony, S. et al. Carbon Dioxide and Climate: Perspectives on a Scientific Assessment. In Hurrell, J. W. \& Asrar, G. (eds.) Monograph on Climate Science for Serving Society: Research, Modelling and Prediction Priorities, 391-413 (Springer Netherlands, Dordrecht, 2013).

7. Boucher, O. et al. Clouds and Aerosols. In Stocker, T. et al. (eds.) Climate Change 2013: The Physical Science Basis. Contribution of Working Group I to the Fifth Assessment Report of the Intergovernmental Panel on Climate Change, 571-657 (Cambridge University Press, Cambridge, United Kingdom and New York, NY, USA., 2013).

8. Sherwood, S. C. et al. Climate Processes: Clouds, Aerosols and Dynamics. In Hurrell, J. W. \& Asrar, G. (eds.) Climate Science for Serving Society, 73-103 (Springer Netherlands, Dordrecht, 2013).

9. Held, I. Simplicity amid Complexity. Science 343, 1206-1207 (2014). 
10. Held, I. M. \& Hou, A. Y. Nonlinear axially symmetric circulations in a nearly inviscid atmosphere. J. Atmos. Sci. 37, 515-533 (1980).

11. Emanuel, K. A. The Dependence of Hurricane Intensity on Climate. Nature 326, 483-485 (1987).

12. Hartmann, D. L. \& Larson, K. An important constraint on tropical cloud - climate feedback. Geophys. Res. Lett. 29, 1951 (2002).

13. Cooke, R., Wielicki, B. A., Young, D. F. \& Mlynczak, M. G. Value of information for climate observing systems. Environ Syst Decis 34, 98-109 (2013).

14. Stevens, B. \& Bony, S. Water in the atmosphere. Physics Today 66, 29 (2013).

15. Rieck, M., Nuijens, L. \& Stevens, B. Marine Boundary Layer Cloud Feedbacks in a Constant Relative Humidity Atmosphere. J. Atmos. Sci 69, 2538-2550 (2012).

16. Zhang, M. et al. CGILS: Results from the first phase of an international project to understand the physical mechanisms of low cloud feedbacks in single column models. J. Adv. Model. Earth Syst. 5, 826-842 (2013).

17. Zhao, M. An Investigation of the Connections among Convection, Clouds, and Climate Sensitivity in a Global Climate Model. J. Clim. 27, 1845-1862 (2014).

18. Zelinka, M. D., Klein, S. A. \& Hartmann, D. L. Computing and Partitioning Cloud Feedbacks Using Cloud Property Histograms. Part I: Cloud Radiative Kernels. J. Clim. 25, 3715-3735 (2012).

19. Butler, A. H., Thompson, D. W. J. \& Heikes, R. The Steady-State Atmospheric Circulation Response to Climate Change-like Thermal Forcings in a Simple General Circulation Model. J. Clim. 23, 3474-3496 (2010).

20. Kang, S. M., Polvani, L. M., Fyfe, J. C. \& Sigmond, M. Impact of Polar Ozone Depletion on Subtropical Precipitation. Science 332, 951-954 (2011). 
21. Brayshaw, D. J., Hoskins, B. \& Blackburn, M. The Basic Ingredients of the North Atlantic Storm Track. Part I: Land-Sea Contrast and Orography. J. Atmos. Sci 66, 2539-2558 (2009).

22. Simpson, I. R., Shaw, T. A. \& Seager, R. A Diagnosis of the Seasonally and Longitudinally Varying Midlatitude Circulation Response to Global Warming. J. Atmos. Sci 71, 2489-2515 (2014).

23. Woollings, T. Dynamical influences on European climate: an uncertain future. Phil. Trans. Roy. Soc. A: Mathematical, Physical and Engineering Sciences 368, 37333756 (2010).

24. Grise, K. M. \& Polvani, L. M. Southern Hemisphere Cloud-Dynamics Biases in CMIP5 Models and Their Implications for Climate Projections. J. Clim. 27, 60746092 (2014).

25. Ceppi, P., Zelinka, M. D. \& Hartmann, D. L. The response of the southern hemispheric eddy-driven jet to future changes in shortwave radiation in cmip5. Geophys. Res. Lett. 41, 3244-3250 (2014).

26. Miyamoto, Y. et al. Deep moist atmospheric convection in a subkilometer global simulation. Geophys. Res. Lett. 40, 4922-4926 (2013).

27. Rivière, G., Laîné, A., Lapeyre, G., Salas-Mélia, D. \& Kageyama, M. Links between Rossby Wave Breaking and the North Atlantic Oscillation-Arctic Oscillation in Present-Day and Last Glacial Maximum Climate Simulations. J. Clim. 23, 29873008 (2010).

28. Bartlein, P. J. et al. Pollen-based continental climate reconstructions at 6 and 21 ka: a global synthesis. Clim. Dynam. 37, 775-802 (2011).

29. Marsham, J. H. et al. The role of moist convection in the West African monsoon system: Insights from continental-scale convection-permitting simulations. Geophys. Res. Lett. 40, 1843-1849 (2013). 
30. Biasutti, M. \& Giannini, A. Robust Sahel drying in response to late 20th century forcings. Geophys. Res. Lett. 33, L11706 (2006).

31. Kang, S. M., Held, I. M., Frierson, D. M. W. \& Zhao, M. The Response of the ITCZ to Extratropical Thermal Forcing: Idealized Slab-Ocean Experiments with a GCM. $J$. Clim. 21, 3521-3532 (2008).

32. Hwang, Y. T. \& Frierson, D. Link between the double-Intertropical Convergence Zone problem and cloud biases over the Southern Ocean. PNAS 110, 4935-4940 (2013).

33. Held, I. M., Delworth, T. L., Lu, J., Findell, K. L. \& Knutson, T. R. Simulation of Sahel drought in the 20th and 21st centuries. Proc. Natl Acad. Sci. USA 102, 1789117896 (2005).

34. Perez-Sanz, A., Li, G., González-Sampériz, P. \& Harrison, S. P. Evaluation of modern and mid-Holocene seasonal precipitation of the Mediterranean and northern Africa in the CMIP5 simulations. Clim. Past 10, 551-568 (2014).

35. Donohoe, A., Marshall, J., Ferreira, D. \& McGee, D. The Relationship between ITCZ Location and Cross-Equatorial Atmospheric Heat Transport: From the Seasonal Cycle to the Last Glacial Maximum. J. Clim. 26, 3597-3618 (2013).

36. Houze Jr, R. A. Cloud clusters and large-scale vertical motions in the tropics. J. Meteor. Soc. Japan 60, 396-408 (1982).

37. Bretherton, C. S., Blossey, P. N. \& Khairoutdinov, M. An energy-balance analysis of deep convective self-aggregation above uniform SST. J. Atmos. Sci 62, 4273-4292 (2005).

38. Tobin, I., Bony, S. \& Roca, R. Observational Evidence for Relationships between the Degree of Aggregation of Deep Convection, Water Vapor, Surface Fluxes, and Radiation. J. Clim. 25, 6885-6904 (2012). 
39. Wing, A. A. \& Emanuel, K. A. Physical mechanisms controlling self-aggregation of convection in idealized numerical modeling simulations. J. Adv. Model. Earth Syst. 6, 59-74 (2014).

40. Seifert, A. \& Heus, T. Large-eddy simulation of organized precipitating trade wind cumulus clouds. Atmos. Chem. Phys. 13, 5631-5645 (2013).

41. Muller, C. J. \& Held, I. M. Detailed Investigation of the Self-Aggregation of Convection in Cloud-Resolving Simulations. J. Atmos. Sci 69, 2551-2565 (2012).

42. Neggers, R. A. J., Neelin, J. D. \& Stevens, B. Impact Mechanisms of Shallow Cumulus Convection on Tropical Climate Dynamics. J. Clim. 20, 2623-2642 (2007).

43. Jakob, C. Accelerating progress in global atmospheric model development through improved parameterization. Bull. Am. Meteorol. Soc. 91, 869-875 (2010).

44. Lorenz, E. N. The nature of the global circulation of the atmosphere: a present view. The General Circulation of the Atmosphere 3-23 (1969).

45. Slingo, A. \& Slingo, J. The response of a general circulation model to cloud longwave radiative forcing. I: Introduction and initial experiments. Q. J. R. Meteorol. Soc. 114, 1027-1062 (1988).

46. Bony, S. \& Emanuel, K. A. On the role of moist processes in tropical intraseasonal variability: Cloud-radiation and moisture-convection feedbacks. J. Atmos. Sci 62(8), 2770-2789 (2005).

47. Chagnon, S., Gray, S. L. \& Methven, J. Diabatic processes modifying potential vorticity in a North Atlantic cyclone. Q. J. R. Meteorol. Soc. 139, 1270-1282 (2013).

48. Joos, H. \& Wernli, H. Influence of microphysical processes on the potential vorticity development in a warm conveyor belt: a case study with the limited area model COSMO. Q. J. R. Meteorol. Soc. 138, 407-418 (2012). 
49. Braconnot, P. et al. Evaluation of climate models using palaeoclimatic data. Nature Clim. Change 2, 417-424 (2012).

50. Martin, G. M. et al. Analysis and Reduction of Systematic Errors through a Seamless Approach to Modeling Weather and Climate. J. Clim. 23, 5933-5957 (2010).

Acknowledgements This paper was developed as part of the Grand Challenge on "Clouds, Circulation and Climate Sensitivity" of the World Climate Research Programme. The process of identifying a handful of scientific questions that have the potential to advance our understanding of the interplay of clouds, circulation and climate sensitivity culminated in a workshop whose participants are gratefuly acknowledged: Dorian Abbot, Peter Bauer, Michela Biasutti, Hervé Douville, JeanLouis Dufresne, Anthony Del Genio, Kerry Emanuel, Qiang Fu, Julia Hargreaves, Sandy Harrison, Isaac Held, Cathy Hohenegger, Brian Hoskins, Sarah Kang, Hideaki Kawai, Stephen A. Klein, Norman Loeb, Thorsten Mauritsen, Brian Mapes, Martin Miller, Caroline Muller, Colin Prentice, Camille Risi, Masaki Satoh, Courtney Schumacher, Bruce Wielicki, Masakazu Yoshimori, and Paquita Zuidema. Marie Doutriaux-Boucher (EUMETSAT) provided the satellite products used in Figure 2. S.B. and B.S. acknowledge support from the LABEX L-IPSL and the Max Planck Society for the Advancement of Science.

Author contributions S.B. and B.S. led the writing of the paper. All authors contributed to the development and writing of the manuscript.

Additional information Correspondence should be addressed to S.B. (email: bony@ @lmd.jussieu.fr).

Competing Interests The authors declare no competing financial interests. 
Figure 1 What role does convection play in cloud feedbacks? Shallow clouds such as those shown on the left (with tops around $2.5 \mathrm{~km}$, and hints of much deeper convection in the distant background) are known to be important in determining the sensitivity of climate system models to perturbations. The behaviour of convection on all scales is thought to be important for determining the response of clouds to a warming climate, particularly for the delicate cloud regimes covering tropical and subtropical oceans.

Figure 2 What controls the position, strength and variability of storm tracks? a A mid-latitude winter storm is outlined by the red dashed line (which demarcates the boundary between air-masses in the upper troposphere) overlain on infrared radiances measured with a geostationary satellite. $\mathbf{b}$ Motion vectors and brightness temperatures are used to deduce the motion and height of the cloud fields from which they are derived. c A conceptual cartoon illustrates the interplay between the circulation and a rich variety of cloud fields along a cross section roughly following the transect shown in panel (a). In $\mathbf{a}-\mathbf{b}$ the data is limited by the field of view of the Meteosat satellite (EUMETSAT).

Figure 3 What controls the position, strength and variability of tropical rainbelts? a Observations (derived from the satellite Tropical Rainfall Measuring Mission) feature a contrasted distribution of precipitation at the regional scale, with large amounts of rainfall occurring in narrow bands of the tropics. b The position of tropical rain bands has a pronounced influence on precipitation over land, with droughts over periods of decades attributable to shifts in the ITCZ, as for instance seen in the Sahel during the 20th Century ${ }^{33}$.

Figure 4 What role does convective aggregation play in climate? a In models convective organisation emerges spontaneously, increasingly so with increasing temperature ${ }^{41}$. b In observations (relative humidity profiles from AIRS satellite measurements) the middle troposphere is drier in an atmosphere in which the 
same amount of precipitation is concentrated in a smaller number of convective clusters $^{38}$.

Figure 5 [Box 1 figure] Clouds are closely coupled to the atmospheric circulation but in ways that we are only beginning to discover. (From SATMOS (CMeteoFrance)

Figure 6 [Box 2 figure] The power of resolving processes across a range of scales. a Simulations of the climate system can now span a range of scales stretching from that of cloud systems (about $1 \mathrm{~km}$ ) through the planetary scales (shown is the mixing ratio of condensed water simulated with a global cloud-resolving model ${ }^{26}$ ). b Observations are now capable of profiling the vertical structure of condensate throughout the atmosphere (shown are vertical profiles of radar reflectivity and clouds from CloudSat and Calipso (CNASA and 2007 TerraMetrics). c Palaeo records are providing an ever richer and more coherent story of past changes in precipitation (shown is a distribution map of reconstructed lake levels across Africa, 9,000 years ago relative to today (C)2012 Nature Education). 

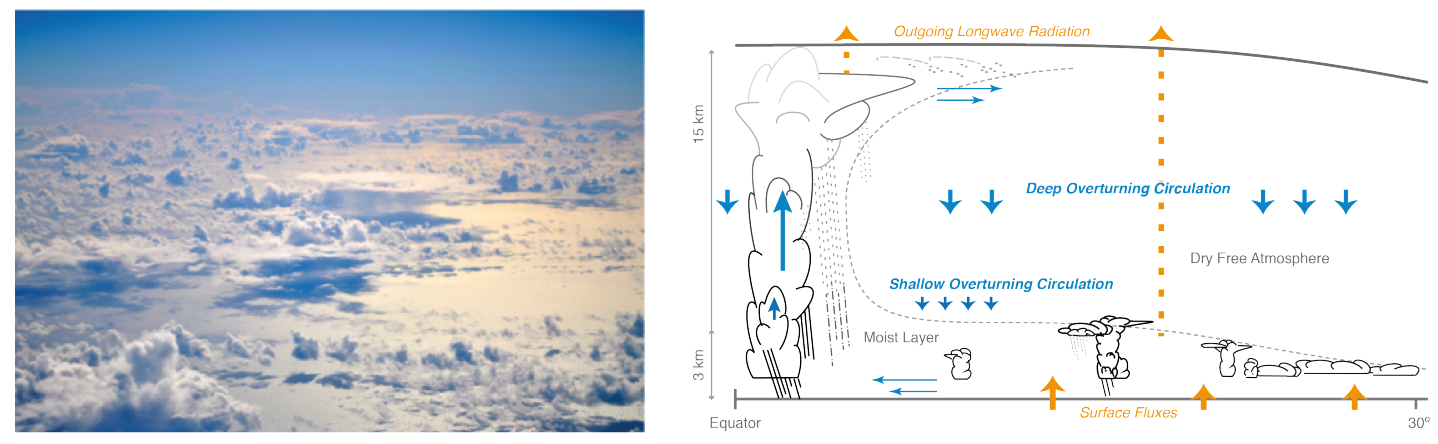

Figure 1: What role does convection play in cloud feedbacks? Shallow clouds such as those shown on the left (with tops around $2.5 \mathrm{~km}$, and hints of much deeper convection in the distant background) are known to be important in determining the sensitivity of climate system models to perturbations. The behaviour of convection on all scales is thought to be important for determining the response of clouds to a warming climate, particularly for the delicate cloud regimes covering tropical and subtropical oceans. 

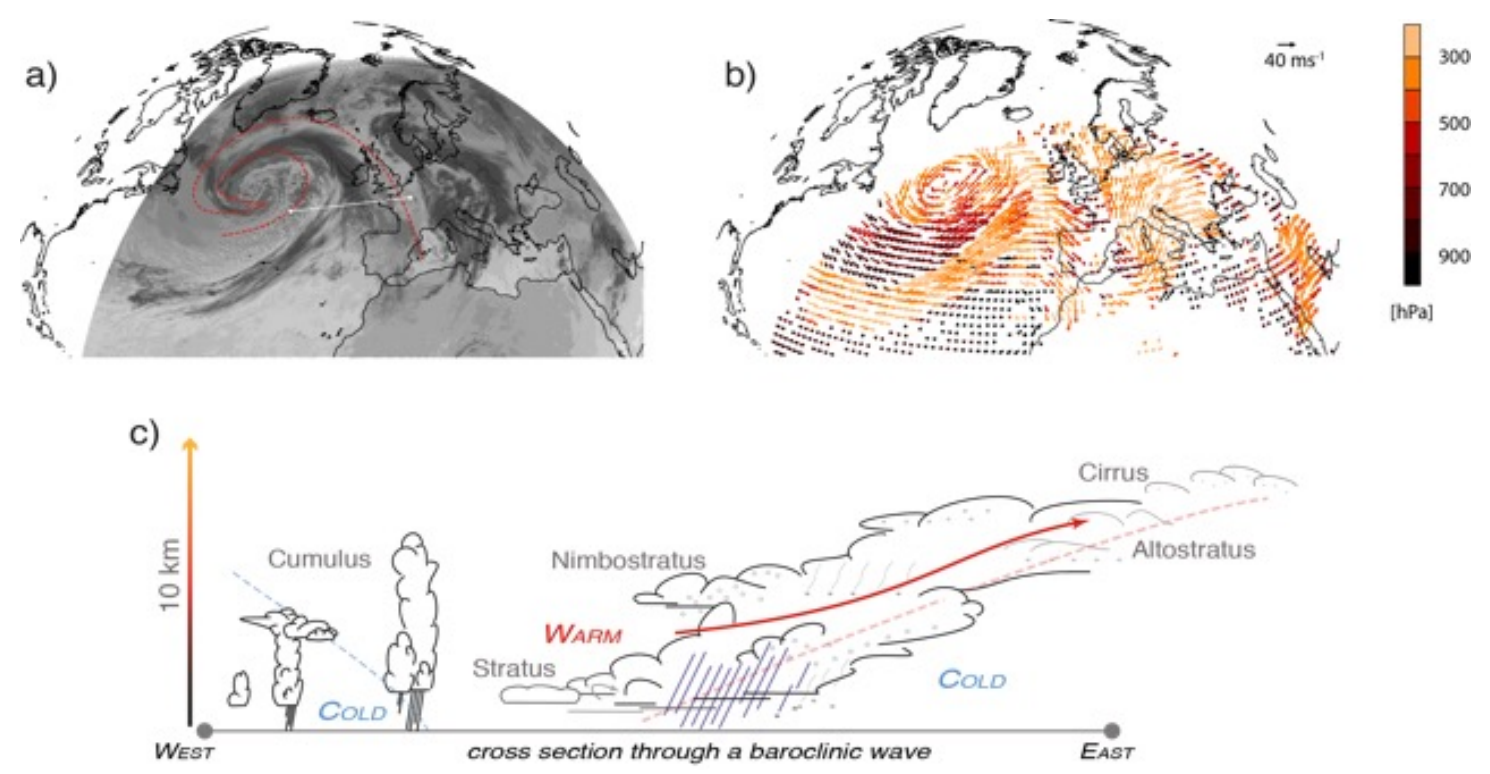

Figure 2: What controls the position, strength and variability of storm tracks? a A midlatitude winter storm is outlined by the red dashed line (which demarcates the boundary between air-masses in the upper troposphere) overlain on infrared radiances measured with a geostationary satellite. $\mathbf{b}$ Motion vectors and brightness temperatures are used to deduce the motion and height of the cloud fields from which they are derived. c A conceptual cartoon illustrates the interplay between the circulation and a rich variety of cloud fields along a cross section roughly following the transect shown in panel (a). In $\mathbf{a}-\mathbf{b}$ the data is limited by the field of view of the Meteosat satellite (EUMETSAT). 
a)

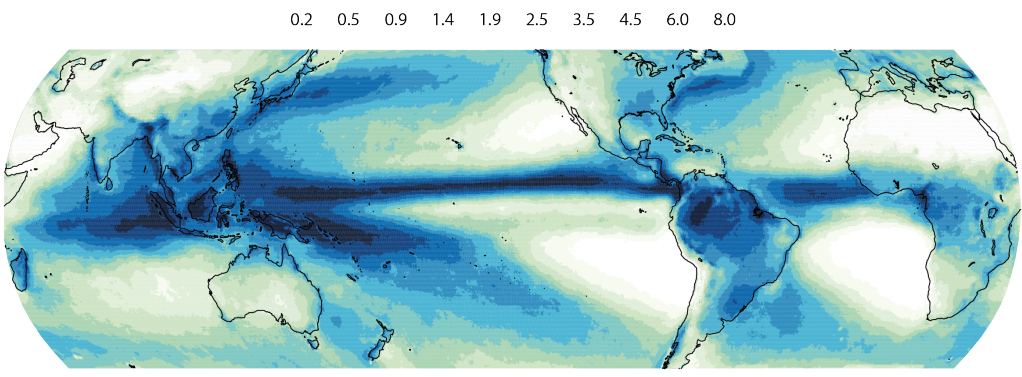

b)

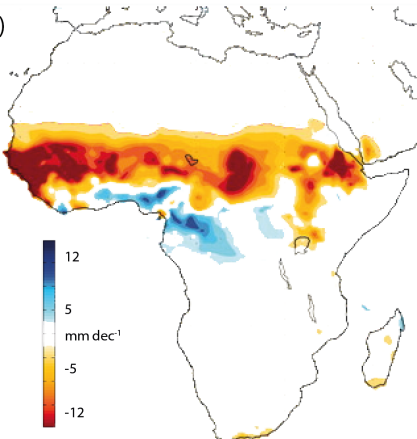

Figure 3: What controls the position, strength and variability of tropical rainbelts? a Observations (derived from the satellite Tropical Rainfall Measuring Mission) feature a contrasted distribution of precipitation at the regional scale, with large amounts of rainfall occurring in narrow bands of the tropics. $\mathbf{b}$ The position of tropical rain bands has a pronounced influence on precipitation over land, with droughts over periods of decades attributable to shifts in the ITCZ, as for instance seen in the Sahel during the 20th Century ${ }^{33}$.

a)
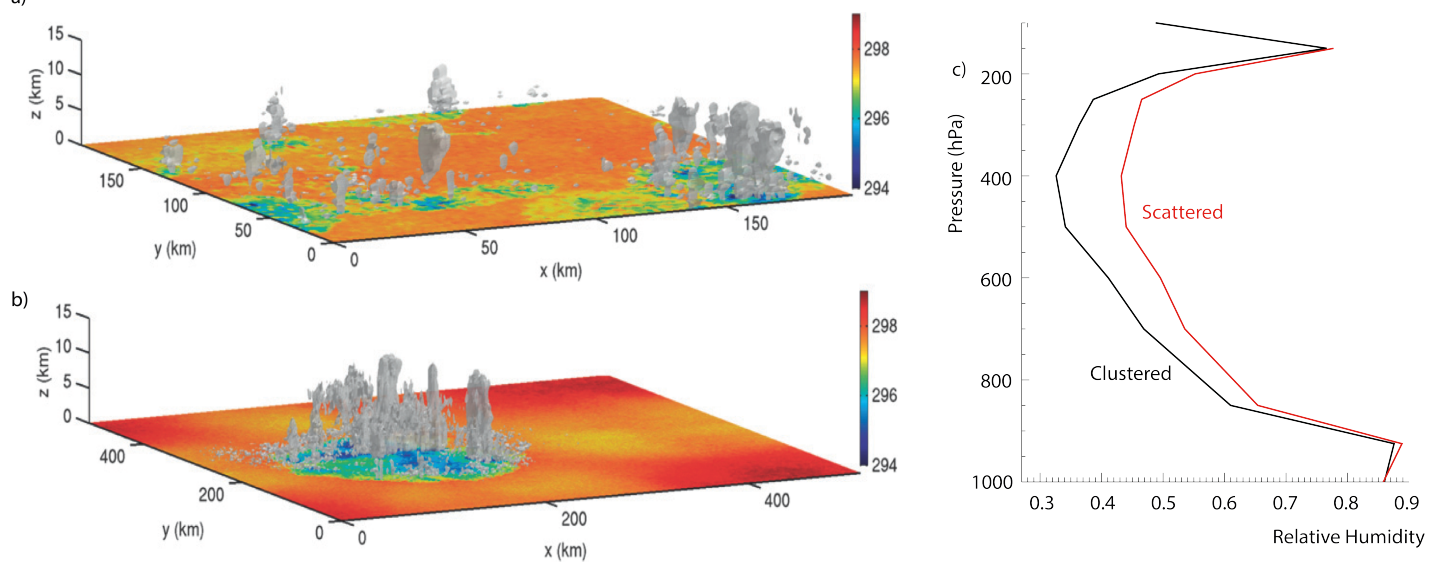

Figure 4: What role does convective aggregation play in climate? a In models convective organisation emerges spontaneously, increasingly so with increasing temperature ${ }^{41}$. b In observations (relative humidity profiles from AIRS satellite measurements) the middle troposphere is drier in an atmosphere in which the same amount of precipitation is concentrated in a smaller number of convective clusters ${ }^{38}$. 


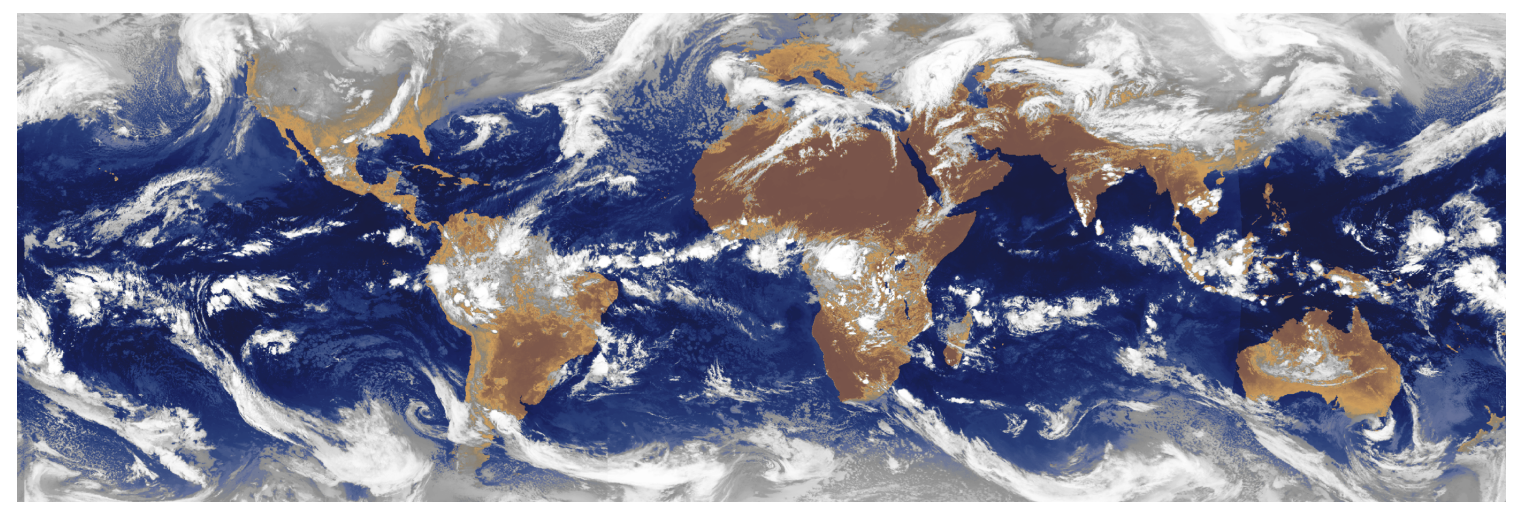

Figure 5: [Box 1 figure] Clouds are closely coupled to the atmospheric circulation but in ways that we are only beginning to discover. (From SATMOS (C)Meteo-France)
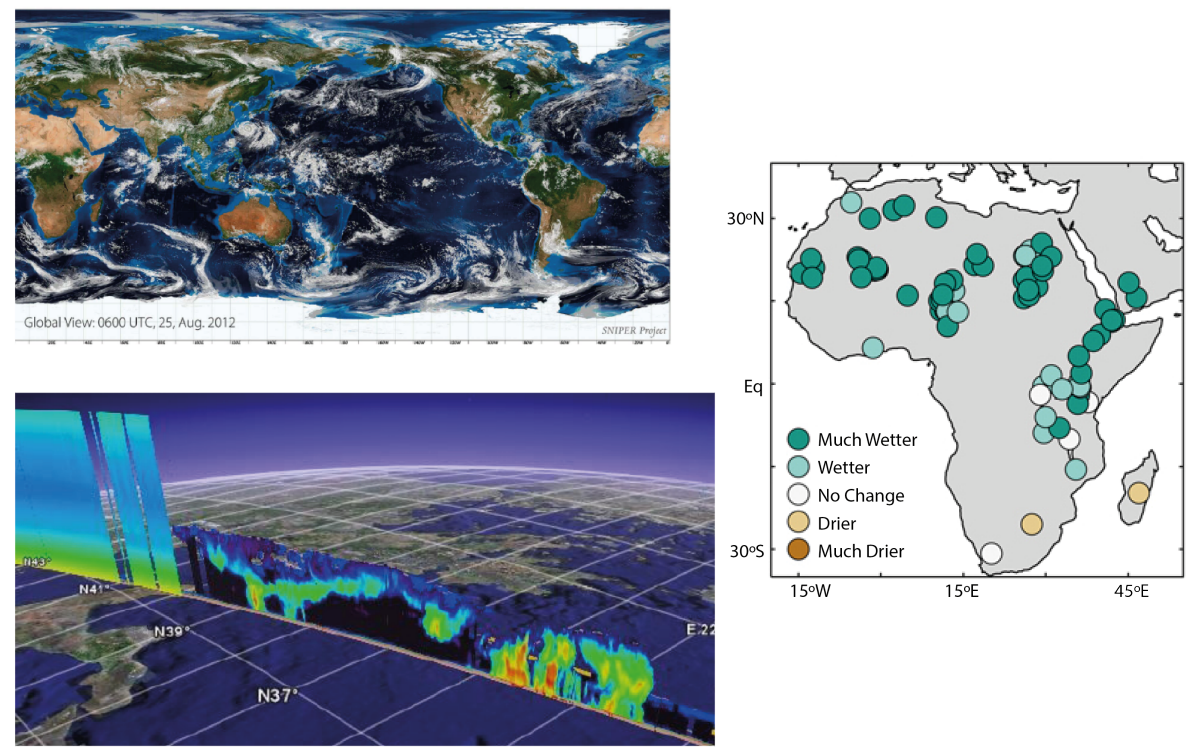

Figure 6: [Box 2 figure] The power of resolving processes across a range of scales. a Simulations of the climate system can now span a range of scales stretching from that of cloud systems (about $1 \mathrm{~km}$ ) through the planetary scales (shown is the mixing ratio of condensed water simulated with a global cloud-resolving model $^{26}$ ). $\mathbf{b}$ Observations are now capable of profiling the vertical structure of condensate throughout the atmosphere (shown are vertical profiles of radar reflectivity and clouds from CloudSat and Calipso (C)NASA and 2007 TerraMetrics). c Palaeo records are providing an ever richer and more coherent story of past changes in precipitation (shown is a distribution map of reconstructed lake levels across Africa, 9,000 years ago relative to today (c)2012 Nature Education). 